\title{
Immunopotentiation of galangal (Alpinia galanga L.) when combined with T-cells against metastatic triple-negative breast cancer, MDA-MB 231
}

\author{
Iffan Alifi, ${ }^{1,2}$ Rohmad Yudi Utomo ${ }^{3,4}$ (D), Faradiba Nur Ahlina ${ }^{3}$, Nadzifa Nugraheni ${ }^{3}$, Dedy Hermansyah ${ }^{5}$, Agung Putra $^{1,7}$ (D), \\ Edy Meiyanto $2,6 *$ (D) \\ ${ }^{1}$ Stem Cell and Cancer Research (SCCR), Universitas Islam Sultan Agung, Semarang, Indonesia. \\ ${ }^{2}$ Biotechnology Study Program, Graduate School, Universitas Gadjah Mada, Yogyakarta, Indonesia. \\ ${ }^{3}$ Cancer Chemoprevention Research Center, Faculty of Pharmacy, Universitas Gadjah Mada, Yogyakarta, Indonesia. \\ ${ }^{4}$ Laboratory of Medicinal Chemistry, Department of Pharmaceutical Chemistry, Faculty of Pharmacy, Universitas Gadjah Mada, Yogyakarta, Indonesia. \\ ${ }^{5}$ Department of Surgery, Faculty of Medicine, Universitas Sumatera Utara, Medan, Indonesia. \\ ${ }^{6}$ Laboratory of Macromolecular Engineering, Department of Pharmaceutical Chemistry, Faculty of Pharmacy, Universitas Gadjah Mada, Yogyakarta, Indonesia. \\ ${ }^{7}$ Department of Pathological Anatomy, Universitas Islam Sultan Agung, Semarang, Indonesia.
}

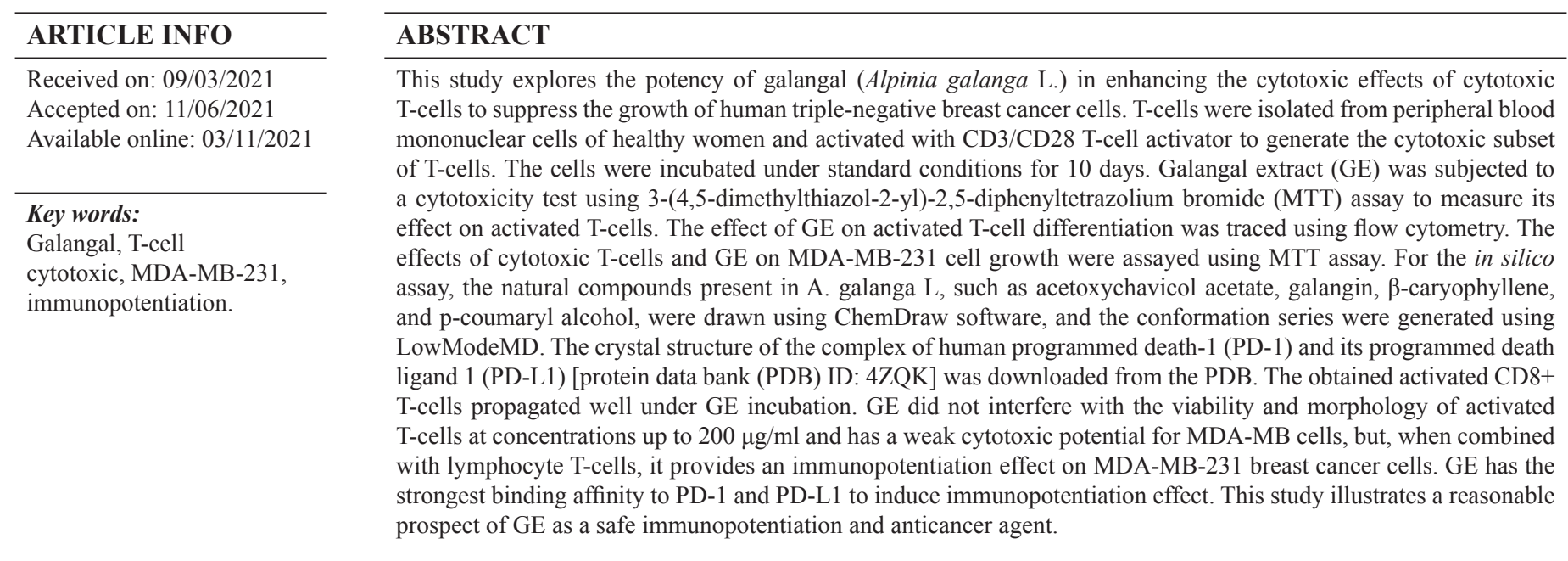

\section{INTRODUCTION}

Most metastatic triple-negative breast cancers (TNBCs) exhibit cancer stem cells (CSC) characteristics, which are tumorigenic self-renewal cells that are usually resistant to

\footnotetext{
${ }^{*}$ Corresponding Author

Edy Meiyanto, Cancer Chemoprevention Research Center, Faculty of Pharmacy, Universitas Gadjah Mada, Yogyakarta, Indonesia and Laboratory of Macromolecular Engineering, Department of Pharmaceutical Chemistry, Faculty of Pharmacy, Universitas Gadjah Mada, Yogyakarta, Indonesia.E-mail: edy_meiyanto@ugm.ac.id
}

chemotherapy and radiotherapy and cause tumor recurrence that is more aggressive in the later stage (Ayob and Ramasamy, 2018). In live-cell cycles, CSC is trapped on the quiescent phase, highly expresses transporter and antiapoptotic genes, and ends up resistant to DNA damage (Park et al., 2009). Moreover, CSC tends to be immune-resistant due to the genetic alteration, which contributes to the loss of tumor antigen expression, antigen processing, and presentation machinery, as well as downregulation of major histocompatibility complex (MHC) class I and inhibition of MHC class II molecule expression on antigen-presenting cell (APC) (Sceneay et al., 2013). In addition, CSC secretes a distinct molecule, for instance, IL-4, IL-6, IL-10, TGF- $\beta$, and PGE-2, 
which protects it from destruction by innate and adaptive immune cells (Bruttel and Wischhusen, 2014). Expression of immuneinhibitory checkpoint molecules such as CTLA4 and programmed death ligand 1 (PD-L1) contributed also to evading immune response (Snyder et al., 2014; Topalian et al., 2012). Hence, CSC is likely able to escape both the innate and adaptive immune systems and then grows excessively.

The immune response to cancer involves two essential components, namely, cytotoxic T-cells (adaptive immune response) and natural killer (NK) cells (innate immune response), each of which has a different mechanism (Janssen et al., 2017). Cancer cells express tumor-specific antigens that can be recognized by both components and subsequently activate the immune system to destroy the cancer cells. CD ${ }^{+}$ cytotoxic T-cells can recognize and kill cancer cells if activated and primed to recognize antigens from tumors through APC. The mutated protein expressed by cancer cells becomes a source of T-cells to identify specifically (Joffre et al., 2012). CD8 T-cells are activated and primed when they recognize the MHC I antigen tumor complex with an intermediate T-cell receptor and then trigger $\mathrm{CD}^{+} \mathrm{T}$-cell proliferation. Then, a cytotoxic effector T-cell pool is formed that is able to recognize all cells expressing tumor-specific antigens and kill cancer cells through induction of apoptosis (Charles et al., 2001).

Notwithstanding, NK cells are not primed to recognize cancer cells or express tumor-specific antigens. However, NK cells recognize cancer cells through specific antigen receptors, such as NKG2D, NCRs, DNAM1, and CD16, which will recognize the ligands that are expressed on the surface of stressed cells, such as cancer cells. When NK cells recognize cancer cells, they will induce apoptosis through granule-mediated-exocytosis or the Fas-Fas ligand axis, which also occurs through $\mathrm{CD}^{+}$cytotoxic T-cells pathways (Wu and Lanier, 2003). Recently, an immunobased cancer therapy strategy focused on streamlining the immune response to eliminate cancer cells.

Along with the immune response, the interaction of programmed death-1 (PD-1) and PD-L1 on the surface of activated $\mathrm{CD}^{+}$T-cytotoxic cells causes inhibition of mediated T-cell antigen activation (Wherry, 2011). Various types of cancer cells, such as breast cancer, express PD-L1, while T-specific antigen cells express the complementary PD-1 receptor (Castagnoli et al., 2019). This interaction causes cancer cells and CSCs to fool the immune system because the immune system considers them normal cells and so they can develop aggressively. Immunosuppressive effects were found in correlation with the high expression of PD-L1 on MDA-MB-231 cells, a human breast cancer cell line (Zheng et al., 2019). Inhibiting the interaction of PD-1 and PDL1 is a promising strategy in increasing the sensitivity of immune cells to cancer cells. Curcumin is known to increase the immune antitumor response by inhibiting the expression of PD-L1 and p-STATY705 in tongue squamous cell carcinoma (Liao et al., 2018). Therefore, a broader search for other compounds that can enhance the immune response to cancer cells is worth considering. The MDA-MB 231 cell line is categorized as TNBC that exhibits metastatic-CSC characteristics (Azadi et al., 2019) and is resistant to some chemotherapeutic agents in correlation with PD-L1 expression (Rom-Jurek et al., 2018). Therefore, MDA-MB 231 is a suitable CSC breast cancer cell model to be used as a target of immunotherapy.

Galangal is known to have the ability to inhibit the growth of cancer cells. Moreover, galangal extract (GE) is known to induce senescence and increase the level of reactive oxygen species (ROS) in metastatic breast cancer cells (Ahlina et al., 2020). Another study also shows that galangal has a cytotoxic activity, which can induce apoptosis in MCF-7 breast cancer cells (Samarghandian et al., 2014). Active compounds of galangal, such as 1'-acetoxychavicol acetate (ACA), can inhibit the growth of oral squamous carcinoma cells in vitro or in vivo by inhibiting the constitutive activation of nuclear factorkappa B through suppression of IKK $\alpha / \beta$ activation. However, other active compounds such as galangin exhibit antimetastatic properties by inhibiting cell migration and expression of MMPs (Chien et al., 2015). Some studies also indicate that GE has the ability to immunomodulate. GE has been reported to modulate T-cell proliferation activity and delayed-type hypersensitivity response. Administering GE with a particular concentration is known to increase T-cell proliferation in vivo (Pal Jain et al., 2012). Nevertheless, administration of 1'-ACA with a certain concentration was reported to suppress lymphocyte cell populations in asthma mouse models (Seo et al., 2013). This shows that GE has potential as a modulator of T-cell development and expansion. Therefore, this study aims to explore the potency at which cytotoxic T-cell activity is maintained and suppresses the growth of TNBC cells.

\section{MATERIALS AND METHODS}

\section{GE preparation and characterization}

Galangal (Alpinia galanga L.) was acquired from the Medical Plant and Traditional Medicine Research and Development Center, Tawangmangu, Ministry of Health, Republic of Indonesia. The galangal was mashed and extracted with $96 \%$ ethanol. The dried oil of GE was collected and used for the following experiment. The extract was then analyzed by using gas chromatography-mass spectrometry [Shimadzu single quadrupole gas chromatography-mass spectrometry (GC-MS)QP2010 ultra] as previously described (Ahlina et al., 2020) to obtain the metabolite profile.

\section{Cancer cell culture}

MDA-MB-231 cancer cell line was purchased from ECACC (Porton Down, Wiltshire, UK). The cells were cultured in Dulbecco's modified Eagle medium-high glucose (Sigma-Aldrich, St. Louis, MO), supplemented with $10 \%$ fetal bovine serum (Gibco, Invitrogen, NY), 1\% penicillin $(100 \mathrm{U} / \mathrm{ml}) /$ streptomycin $(100 \mu \mathrm{g} / \mathrm{ml})(\mathrm{Gibco}$, Invitrogen, NY), and $0.25 \%$ amphotericin B (Gibco, NY) under standard conditions $\left(37^{\circ} \mathrm{C}\right.$ and $\left.5 \% \mathrm{CO}_{2}\right)$.

\section{T-cell isolation}

Ethical clearance for the use of peripheral blood mononuclear cells (PBMCs) isolated from a healthy woman was obtained from the Research Bioethics Committee of Faculty of Medicine, Universitas Islam Sultan Agung, Semarang, Indonesia (approval number, No. 010/I/2020/Komisi Bioetik). Written informed consent was obtained from the patient prior to the 
PBMCs isolation. The T-cells were isolated from PBMCs of healthy women obtained from buffy coats. PBMCs were separated using density gradient centrifugation on Ficoll-Paque (SigmaAldrich, St. Louis, MO). The T-cells were isolated using the EasySep Human T-cell Isolation Kit (STEMCELL Technologies, Vancouver, Canada), according to the manufacturer's instructions. Briefly, PBMCs were resuspended in $1 \mathrm{ml}$ RoboSep Buffer (STEMCELL Technologies, Vancouver, Canada) using a $5 \mathrm{ml}$ (12 $\times 75 \mathrm{~mm}$ ) polystyrene round bottom test tube (Corning, NY). The cell suspension was incubated with $50 \mu$ EasySep Human T-Cell Enrichment Cocktail (STEMCELL Technologies, Vancouver, Canada) at room temperature for 5 minutes. Then, $40 \mu 1$ EasySep Dextran RapidSpheres (STEMCELL Technologies, Vancouver, Canada) was added, and the cell suspension was made to a total volume of $2.5 \mathrm{ml}$ by adding the buffer. The cell suspension was placed into EasySep Magnet (STEMCELL Technologies, Vancouver, Canada) for 3 minutes to separate the T-cells. Then, the isolated T-cells were transferred into a different tube for the following experiment.

\section{Cytotoxic T-cell generation}

Isolated T-cells were cultured in ImmunoCult-XF T-cell Expansion Medium (STEMCELL Technologies, Vancouver, Canada), containing $1 \%$ penicillin $(100 \mathrm{U} / \mathrm{ml}) /$ streptomycin (100 $\mu \mathrm{g} / \mathrm{ml})$ (Gibco, Invitrogen, Grand Island, NY), 0.25\% amphotericin B (Gibco, Grand Island, NY), and 0.125\% Human Recombinant IL-2 (STEMCELL Technologies, Vancouver, Canada). The cultured cells were also incubated with $2.5 \%$ ImmunoCult ${ }^{\mathrm{TM}}$ Human CD3/CD28 T-cell activator for generating the cytotoxic subset of T-cells. The cells were incubated under standard conditions for 10 days. The medium was renewed every 2-3 days with a completely fresh one.

\section{3-(4,5-dimethylthiazol-2-yl)-2,5-diphenyltetrazolium bromide (MTT) assay}

For a single MTT treatment, after direct coculture for 24 hours, the activated T-cells and treatment medium were discarded. The attached cells were washed using phosphate-buffered saline (PBS) (Gibco, Grand Island, NY). Cells were then incubated with MTT reagent (Sigma-Aldrich, St. Louis, MO) for 4 hours and with dimethyl sulfoxide for 15 minutes, and the absorbance was measured using a microplate reader (Bio-Rad, Hercules, CA) at a wavelength of $595 \mathrm{~nm}$. For analyzing the interaction of activated T-cells and MDA-MB-231 under GE stimulation, a direct coculture model was performed. The MDA-MB-231 cell line was cultured into a 96-well plate at a concentration of $5 \times 10^{4}$ cells $/ \mathrm{ml}$ using the standard medium for 24 hours. Then, the attached cells were treated with a standard medium containing various concentrations of GE for 24 hours. The cells were also cocultured with activated T-cells at the concentration ratios of 3:1, 1:1, and 1:3 (activated T-cells: MDA-MB-231) with several concentrations of GE for 24 hours at $37^{\circ} \mathrm{C}$ and $5 \% \mathrm{CO}_{2}$.

\section{Flow cytometry analysis of GE-stimulated T-cells}

The cells were cultured in 6-well plates and incubated with $25 \mu \mathrm{g} / \mathrm{ml} \mathrm{GE}$ or standard medium for 24 hours. Then, cells were collected and pelleted at 1,900 rpm for 10 minutes at $4^{\circ} \mathrm{C}$ by washing with PBS. The pellets were subsequently stained with fluorescein isothiocyanate, allophycocyanin (APC), peridininchlorophyll-protein, and phycoerythrin- conjugated anti-human CD3, CD4, CD45, and CD8 (BD Biosciences, San Jose, CA). After 30 minutes of incubation at room temperature in the dark, the cells were washed and analyzed on a BD Accuri C6 Plus flow cytometer (BD Biosciences, San Jose, CA). The data were analyzed using the BD Accuri C6 Plus software (BD Biosciences, San Jose, CA).

\section{Molecular docking}

Following the method of Hermawan et al. (2019), MOE docking was used. The natural compounds in A. galanga $L$, such as ACA, galangin, $\beta$-caryophyllene, and p-coumaryl alcohol, were drawn using ChemDraw software and the conformation series was generated using LowModeMD. The crystal structure of the complex of human PD-1 and its ligand PD-L1 [protein data bank (PDB) ID: 4ZQK] was downloaded from the PDB. All of the unnecessary molecules were removed, including the cofactors and water. For binding site screening, we focused on the interaction site of PD-L1 with PD-1. The docking screening was conducted using MMF94x as a forcefield method and London $\mathrm{dG}$ as the scoring function. The compound with the lowest docking score was isolated, and the binding interaction site was visualized.

\section{Statistical analysis}

All data were presented as mean $\pm \mathrm{SE}$. The calculations were carried out using SPSS 23.0 (IBM Corp., Armonk, NY). The statistical analysis was performed using the Student's paired $t$-test. $p$ values $<0.05$ were considered significant.

\section{RESULTS}

\section{Cytotoxic T-cell isolation, culture, and activation}

This study aims to explore galangal potency at which cytotoxic T-cell activity is maintained and suppresses the growth of TNBC cells, that is, MDA-MB cells, a human breast cancer cell line. Initially, the cytotoxic T-cells obtained from the blood of healthy woman were propagated and activated. Cytotoxic T-cells that we used are derived from the isolation of healthy donor blood using immunomagnetic cell sorting techniques based on CD3 markers to sort CD3 naive T-cell clones from PBMCs. Naive T-cells are then cultured using a serum-free medium supplemented with IL-2 and activated using anti-CD3 and CD28. The cells were then cultured for 10 days to obtain $\mathrm{CD}^{+}$cytotoxic T-cell clones with characteristic colony formation. The morphological picture of the activation process of $\mathrm{CD} 8^{+}$cytotoxic T-cells is shown in Figure 1a. T-cells appeared spherical, did not stick to culture plastic, and formed larger colonies until the 10th day. Colony length and area are measured to determine the relative activity of T-cell proliferation. The analysis results showed that the length and area of $\mathrm{CD}^{+}$cytotoxic T-cell colonies increased and peaked on day 10 (Fig. $1 \mathrm{~b}$ and $\mathrm{c}$ ). The obtained activated $\mathrm{CD}^{+} \mathrm{T}$-cells propagated well, and their growth curves were exponential until the 10th day. These results indicate that they can be used as a model for MDAMB-231 breast cancer. Although the T-cells continued to grow 

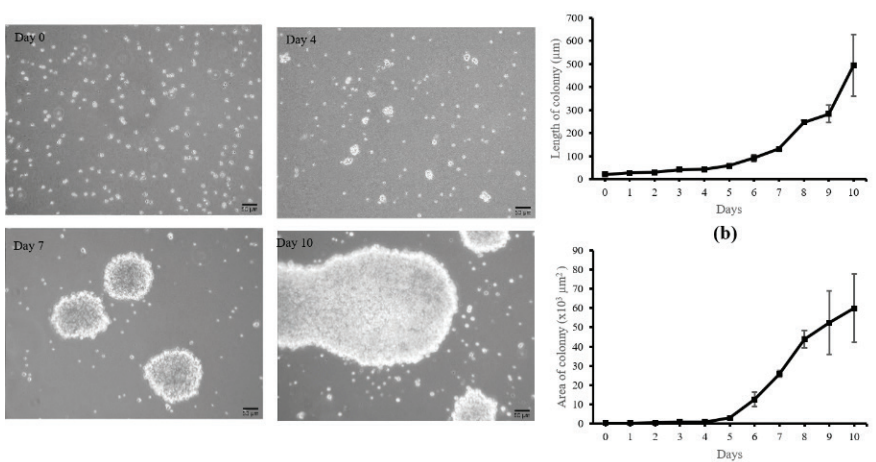

(a)

(c)

Figure 1. Cytotoxic T-cell culture and activation. (a) The colony appearance of T-cells after CD3/CD28 activation in vitro; scale bar $50 \mu \mathrm{m}$. The length (b) and area (c) of activated T-cells colony at days $0-10$. The calculation of length and area of activated T-cells was performed in triplicate.

exponentially until the 10th day, the activation was stopped so that the T-cells remained in optimal condition.

\section{Effects of GE on cytotoxic T-cell growth}

In this study, GE is proposed to enhance or provide a synergistic effect with T-cells lymphocyte to suppress the breast cancer cells, MDA-MB. It should be noted that GE does not affect the viability of T-cells in specific concentrations. Therefore, using MTT assay, GE was evaluated for cytotoxicity at concentrations of 1-200 $\mu \mathrm{g} / \mathrm{ml}$ (Ahlina et al., 2020). The result showed that GE with concentrations up to $200 \mu \mathrm{g} / \mathrm{ml}$ did not affect the cell viability and morphology (Fig. 2a and b). Thus, GE is not cytotoxic to T-cells and can be combined with T-cells at a concentration of $200 \mu \mathrm{g} / \mathrm{ml}$.

\section{Effects of GE on cytotoxic T-cell differentiation}

Cytotoxic T-cells that have been propagated for 10 days are then collected and cultured with GE at a concentration

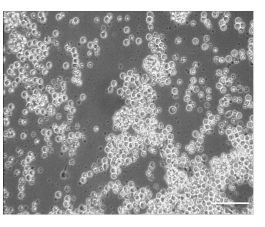

Untreated

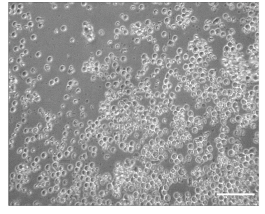

GE $3.125 \mu \mathrm{g} / \mathrm{mL}$

A

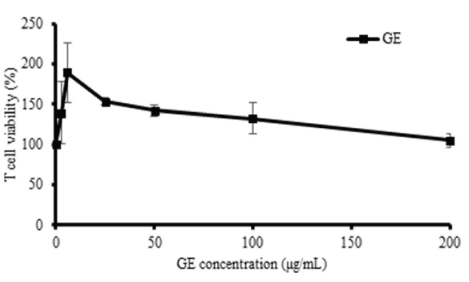

B

Figure 2. Effects of GE on cytotoxic T-cell growth. Cytotoxic T-cells were cultured in the presence of several concentrations of GE for 24 hours and then were evaluated by trypan blue exclusion assay. (a) The appearance of cytotoxic T-cells; (b) the profile of T-cell viability after a single treatment of GE with various concentrations $(1-200 \mu \mathrm{g} / \mathrm{ml})$. (a)

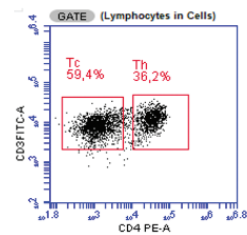

(b)

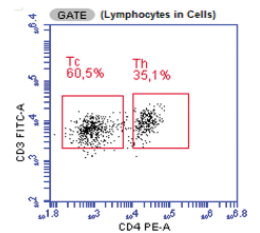

(c)

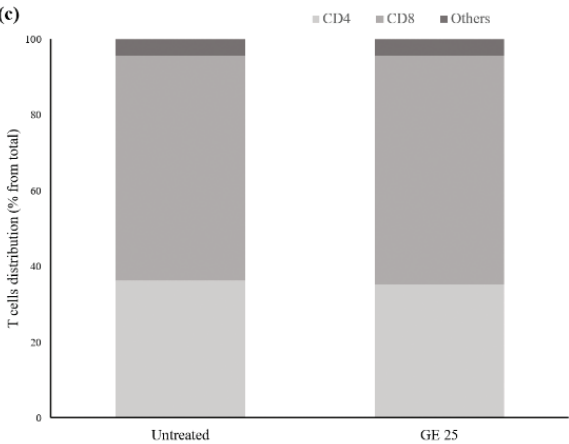

Figure 3. Flow cytometry analysis of cytotoxic T-cells after GE stimulation. The cytotoxic T-cell population was evaluated based on the $\mathrm{CD}^{+}$and $\mathrm{CD} 8^{+}$marker distribution after the treatment of (a) standard medium and (b) GE $25 \mu \mathrm{g} / \mathrm{ml}$ for 24 hours. (c) Quantification of T-cell markers distribution.

of $25 \mu \mathrm{g} / \mathrm{ml}$ for 24 hours. Cytotoxic T-cell culture treated with GE (Fig. 3a) and untreated medium (Fig. 3b) were analyzed using flow cytometry based on $\mathrm{CD}^{+}$and $\mathrm{CD}^{+}$markers to identify the activated cytotoxic T-cell populations after treatment. Flow cytometry analysis showed that the number of cytotoxic T-cell populations did not differ after the addition of GE $(60 \%)$ compared with the untreated medium (59\%) (Fig. 3c). Therefore, we assumed that GE did not affect the activated T-cells.

\section{Effects of cytotoxic T-cells and GE on MDA-MB-231 cell growth}

To determine the immunomodulatory potency of GE, we performed a cytotoxic test and MTT assay on GE and a combination of T-lymphocytes cells and MDA-MB cells with a certain ratio. The results illustrated that GE inhibits MDA-MB cells in a dosedependent manner with inhibitory concentration $160 \mu \mathrm{g} / \mathrm{ml}$ (Fig. 4a). GE had an inhibitory effect on the combination of lymphocyte T-cells and MDA-MB cells at the ratios of 1:3 (Fig. 4b) and 1:1 (Fig. 4c), similar to the effect of single treatment on MDA-MB cells. Interestingly, the cell viability decreased significantly $(p<$ 0.05 ) after administration of GE in the same dose at a ratio of 3:1 of lymphocyte T-cells and MDA-MB, respectively (Fig. 4d). This means those combinations may potentiate the lymphocyte T-cell cytotoxicity against MDA-MB breast cancer cells. Thus, these findings indicate that GE has a weak cytotoxic potential against MDA-MB cells, but its combination with lymphocyte T-cells provides an immunomodulatory effect characterized by an increased toxic effect on MDA-MB breast cancer cells. GE is known to induce senescence and increase the level of ROS in metastatic breast cancer cells (Ahlina et al., 2020). Though GE is also able to increase T-cell proliferation and expansion ( $\mathrm{Pal}$ Jain et al., 2012), its ability to provide a cytotoxic effect when combined with T-lymphocyte cells is not yet known. Therefore, further research is needed to explore the chemical content of GE, which plays a role in the immunomodulatory effect.

\section{Metabolites profile of GE under GC-MS}

Galangal pharmacological effects certainly correlate to its metabolite content. Therefore, we analyzed GE using GC-MS. In this study, we used ethanol solvent to obtain GE extracts, which 

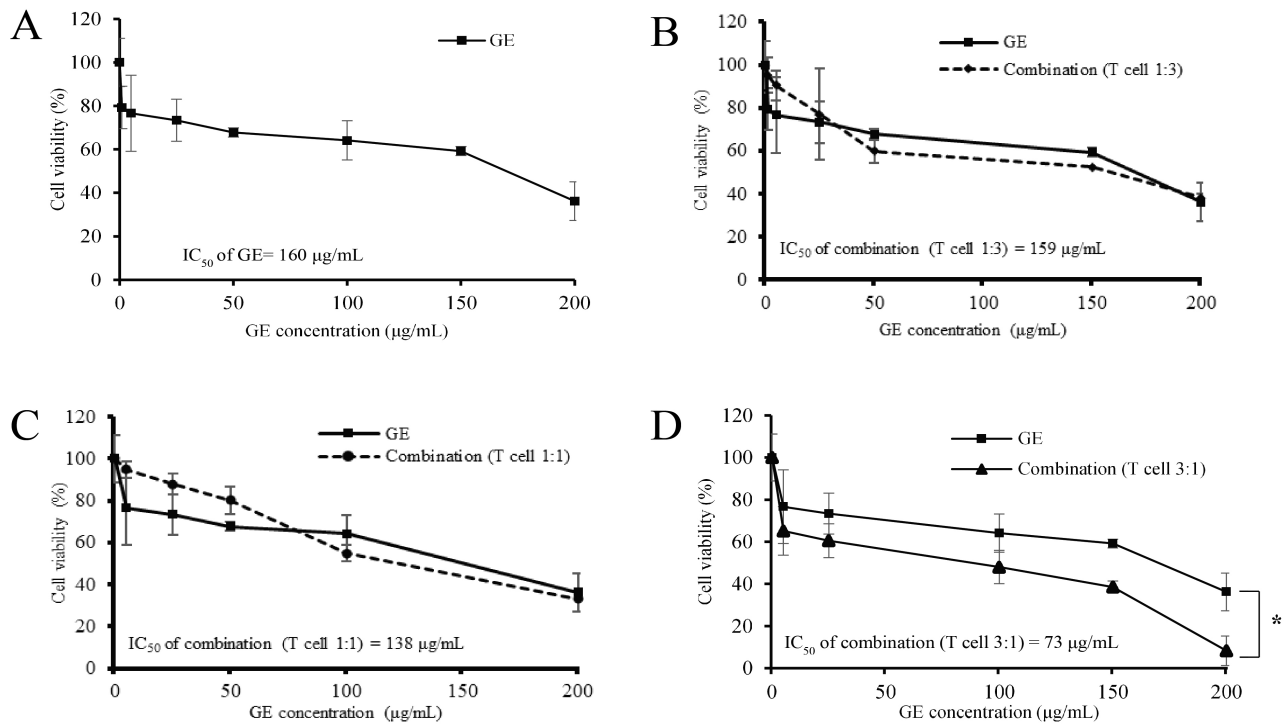

Figure 4. Effects of cytotoxic T-cells and GE on MDA-MB-231 cell growth. Cytotoxic T-cells were cocultured with MDA-MB-231 cells in a particular ratio of cell concentration and then treated with GE in series of concentrations $(1-200 \mu \mathrm{g} / \mathrm{ml})$ for 24 hours and evaluated using MTT assay. The graphs represent the cell viability profiles of MDAMB 231 with GE treatment. (a) Only MDA-MB. (b) Cytotoxic T-cells: MDA-MB = 1:3. (c) Cytotoxic T-cells: MDA$\mathrm{MB}=1: 1$. (d) Cytotoxic T-cells: MDA-MB = 3:1. The MTT was performed in triplicate.

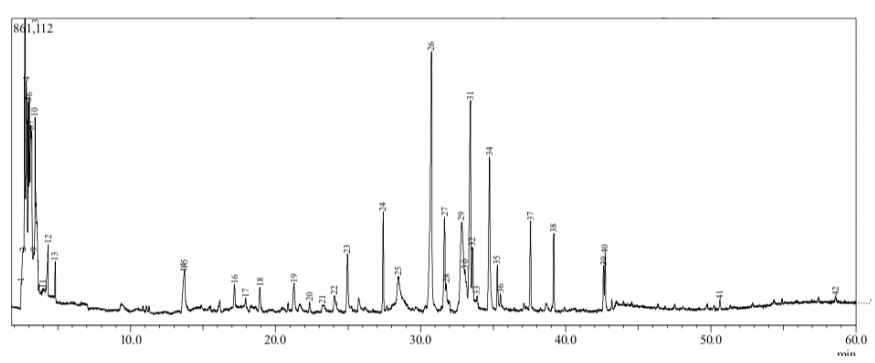

Figure 5. Profile of GE metabolites using GC-MS.

were oil extracts. We consequently examined the chemical content with GC/MS to get the essential oil profile in the extract (Fig. 5). There were more than 28 compounds identified in GE. However, the remarkable compounds that may contribute to GE cytotoxic and immunomodulatory effects against cancer cells were chavicol, $\beta$-caryophyllene, $\mathrm{p}$-coumaryl alcohol, and eugenol (Table 1).

This finding was not similar to other research findings in terms of qualitative and quantitative chemical compositions (Ahlina et al., 2020) that is possibly due to the variety in environmental factors such as soil, temperature, and light which affect the accumulation of secondary metabolites as well as the extraction method (Yang et al., 2018). However, we realized that most of the GE compounds detected in this experiment shared their qualitative composition with other findings. Some of the chemical contents demonstrate anticancer and immunomodulatory significance. Hence, the study of GE metabolic profiles in terms of their immune response in cancer needs to be explored further.

\section{Identification of PD-L1/PD-1 hotspot}

Since the interaction of PD-L1 with PD-1 contributes to cancer cells evading the immune response, we examined the interaction of PD-L1 with PD-1 in silico to ensure whether this interaction occurred intensively. In this study, we used MOE software to visualize the PD-L1/PD-1 hotspot using the reported crystal structure (Zak et al., 2015). Our visualization study revealed that PD-L1/PD-1 contained three hotspots of which one had multiple H-bond donors and acceptors. Several amino acids from PD-L1 such as Asp122, Tyr123, Lys124, and Arg125 form an H-bond with Gln75, Thr76, Asp77, and Lys78 from PD-1 (Fig. 6). The typical surface of this hotspot, however, was shallow and quite challenging to be targeted by a small molecule. Hence, the identification of a compound interacting with this hotspot could provide further knowledge on the PD-L1/PD-1 blockade effect.

\section{The binding interaction of Galangal compounds on PD-L1}

Our computational study on identification of PD-L1/ PD-1 interaction highlighted the presence of a shallow hotspot as the important target site and encouraged us to screen for the possible affinity of active compounds of GE. First, we docked four main chemical contents of GE (Table 1) with the PD-L1 receptor. For validation, the molecular docking was conducted at all three hotspots of PD-L1/PD-1 interaction. Interestingly, the results showed that all GE contents interacted on a shallow hotspot of PD-L1 receptors mediated by arene-H-bond from the benzene ring of each compound with Lys 124 (Fig. 7). In addition, they provided a variation of $\Delta \mathrm{G}$ binding energy (Gibbs energy), which was represented by docking scores between the compounds and the receptor (Table 2). The negative docking score results indicated that the GE content possessed a strong affinity. The most durable bond was found in the galangin, with a docking score of -7.69 (Table 2) indicating that galangin might have a stronger inhibitory effect on the interaction between the cancer cells and the activated T-cells than that of the other compounds. Although this is computational molecular modeling, it showed that the GE 
Table 1. Main GE compounds detected by GC-MS.

\begin{tabular}{cclcc}
\hline No. & Peak number & \multicolumn{1}{c}{ Compound } & Retention time & Abundance \\
\hline 1. & 15 & Succinic aldehyde & 13.727 & $0.84 \%$ \\
2. & 19 & Coumarin & 21.269 & $1.08 \%$ \\
3. & 23 & Chavicol & 24.953 & $1.68 \%$ \\
4. & 24 & $\beta$-Caryophyllene & 27.415 & $2.16 \%$ \\
5. & 25 & p-Hydroxybenzyl alcohol & 28.468 & $1.46 \%$ \\
6. & 26 & p-Coumaryl alcohol & 30.742 & $11.37 \%$ \\
7. & 27 & Eugenol & 31.645 & $2.89 \%$ \\
8. & 29 & p-Coumaryl alcohol & 32.825 & $7.20 \%$ \\
9. & 30 & $\beta$-Caryophyllene epoxide & 33.058 & $1.89 \%$ \\
10. & 31 & Oxiranecarboxylic acid & 33.426 & $7.74 \%$ \\
11. & 32 & Eugenol & 33.568 & $2.01 \%$ \\
12. & 34 & p-Coumaryl alcohol & 34.75 & $5.71 \%$ \\
\hline
\end{tabular}
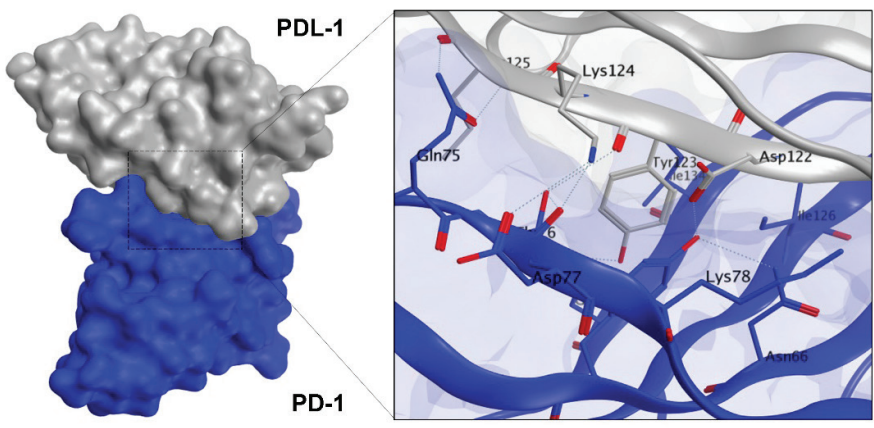

Figure 6. Binding interaction of PD-L1 with PD-1. Structure of PD-L1 and PD-1 is represented as surface or ribbon in silver or blue color.

compounds may have an effect on immune cells that need to be further explored.

\section{Binding interaction of several natural compounds of galangal on PD-1}

Furthermore, we evaluated whether GE metabolites, including chavicol (ACA), beta-caryophyllene, galangin, and p-coumaryl alcohol, can also bind to PD-1, a receptor expressed by T-lymphocyte cells, which is believed to recognize foreign substances to be destroyed by the immune system. In this experiment, we included galangin that is not shown in the GCMS result due to its nonvolatile substance of galangin. However, galangin is known as the main active compound occurring in galangal (Upadhye et al., 2018) which can be detected by using HPTLC or liquid chromatography-mass spectrometry. Following the same procedure of molecular docking on PD-L1, we screened the possible affinity of active compound in GE to PD-1. The $3 \mathrm{D}$ visualization results illustrated that the fourth GE chemical content could bind to the shallow hotspots of PD-1 by forming arene-H-bond and H-bond with Asp 77, Lys 78, and Ile 126 (Fig. 8). Though they give similar amino acid residues for binding, they provide a variation of $\Delta \mathrm{G}$ binding energy (Gibbs energy), which represented the affinity. As found in PD-L1, galangin also had the strongest affinity with a docking score of -8.63 (Table 2). Binding of galangin with lymphocyte T-cells receptor

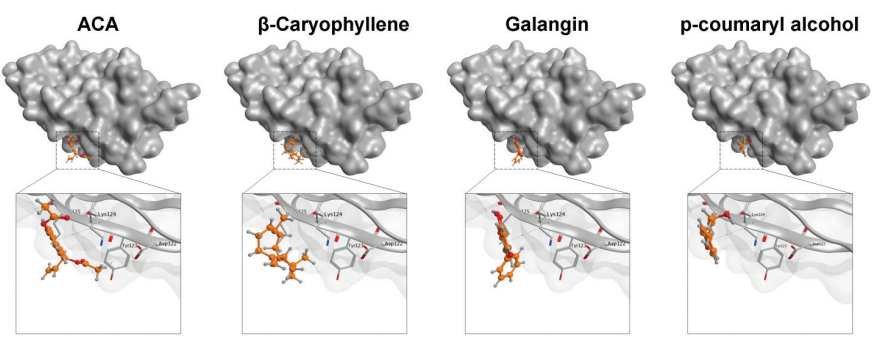

Figure 7. Binding interaction of several natural compounds of galangal on PDL1. Structure of PD-L1 is represented as surface or ribbon in silver color, while the compound is represented as an orange ball-and-stick model.

could trigger immune cells to block PD-L1/PD-1 interaction on cancer cells leading to recognition of cancer cells as foreign invaders that need to be destroyed. Further study related to the galangin content of GE concerning this binding characteristic needs to be explored.

\section{DISCUSSION}

Although GE is a crude extract, it has four significant compounds commonly found in GE and demonstrated pharmacological effects. Using GC-MS, the GE metabolite profile showed that GE contains several essential oils that can inhibit cancer development. We note that ACA (chavicol), $\beta$-caryophyllene, $\mathrm{p}$-coumaryl alcohol, and eugenol, which are commonly found in abundant amounts in GE, demonstrate anticancer properties covering cytotoxic and immunomodulatory effect (Table 3). Chavicol tends to play a role in inhibiting inflammatory signaling pathways, whereas $\beta$-caryophyllene halts cell proliferation through cell cycle arrest and apoptosis induction (Fidyt et al., 2016; Min et al., 2009). Both p-coumaryl alcohol and eugenol, besides contributing to the cytotoxic effect on cancer cells, also play a role in immunomodulation that may potentiate the T-cytotoxic cells toxicity against cancer cells. These different roles could offer a synergistic effect to combat cancer development. Even though there is still limited evidence in terms of in vitro and in vivo studies, the findings of this study show that 
Table 2. Docking scores of several compounds of GE with PD-L1 and PD-1 interaction.

\begin{tabular}{|c|c|c|c|c|}
\hline \multirow{2}{*}{ Ligand } & \multicolumn{2}{|c|}{ PD-L1 } & \multicolumn{2}{|c|}{ PD-1 } \\
\hline & $\Delta$ Gibbs (kcal/mol) & RMSD (Å) & $\Delta$ Gibbs (kcal/mol) & RMSD $(\AA)$ \\
\hline ACA & -5.75 & 1.649 & -6.77 & 2.012 \\
\hline Galangin & -7.69 & 1.619 & -8.63 & 1.446 \\
\hline$\beta$-Caryophyllene & -6.29 & 0.388 & -6.97 & 0.006 \\
\hline p-Coumaryl alcohol & -4.78 & 1.139 & -6.73 & 1.54 \\
\hline
\end{tabular}
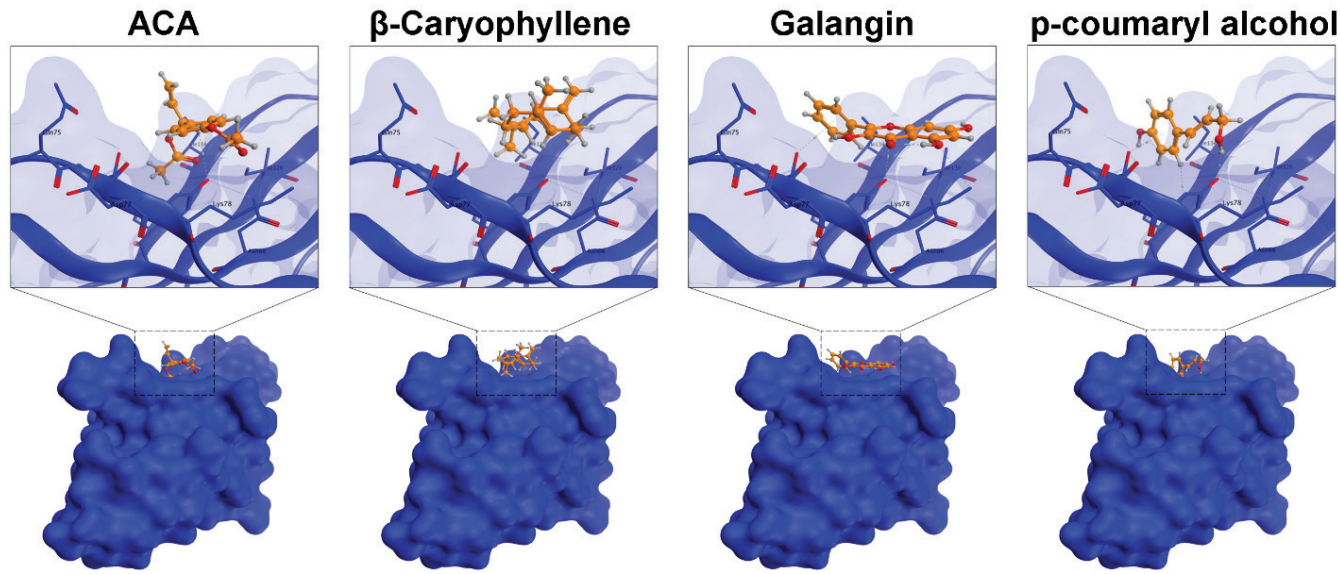

Figure 8. Binding interaction of several natural compounds of galangal on PD-1. Structure of PD-1 is represented as surface or ribbon in blue color, while the compound is represented as an orange ball-and-stick model.

Table 3. The main GE chemical contents with cytotoxic and immunomodulatory activities against cancers.

\begin{tabular}{|c|c|c|c|c|}
\hline No. & Compound & Abundance (\%) & Activity & References \\
\hline 1 & Chavicol & $1.68 \%$ & $\begin{array}{l}\text { Chavicol analog (hydroxychavicol acetate) T-bet } \\
\text { expression may be beneficial as therapeutics for } \\
\text { treating inflammatory immune disorders }\end{array}$ & Min et al., 2009 \\
\hline 2 & $\beta$-Caryophyllene & $2.16 \%$ & $\begin{array}{l}\text { Anticancer and analgesic } \\
\text { Antiviral against HSV-1 } \\
\text { Induces cancer cell cycle arrest and is apoptotic }\end{array}$ & $\begin{array}{l}\text { Arul et al., 2020; Astani et al., } \\
\text { 2011; Fidyt et al., 2016; Klauke et } \\
\text { al., } 2014\end{array}$ \\
\hline 3 & $\begin{array}{l}\text { p-Coumaryl } \\
\text { alcohol }\end{array}$ & $11.37 \%$ & $\begin{array}{l}\text { Suppresses IFN } \gamma \text { production in CD4+ Th cells by } \\
\text { decreasing T-bet expression }\end{array}$ & Yu et al., 2009 \\
\hline 4 & Eugenol & $2.89 \%$ & $\begin{array}{l}\text { Downregulates the Th1 cytokines and concurrent } \\
\text { activation of } \mathrm{Th} 2 \text { response } \\
\text { Induces apoptosis cancer cells }\end{array}$ & $\begin{array}{l}\text { Jaganathan and Supriyanto, 2014; } \\
\text { Kar Mahapatra et al., } 2011\end{array}$ \\
\hline
\end{tabular}

GE compounds can potentially inhibit cancer cell growth and increase the sensitivity of immune cells to cancer cells. However, how the compounds can interact with lymphocyte T-cell receptors and MDA-MB cells needs to be further explored using molecular docking modeling.

This study provides exciting information that GE when combined with T-cells can have a cytotoxic effect on MDA-MB cells. One possible mechanism is that the GE compounds can interfere with the interaction between PD-1 and PD-L1. The docking results support this hypothesis. It is essential to further explore this mechanism because it can support the development of natural-based cancer immunotherapy. PD-L1 is also commonly expressed by metastatic cancer cells and resistant stem cells
(Raniszewska et al., 2019). Therefore, the results of this study can also encourage the development of natural products that can be used to overcome malignancy and cancer resistance. MDA-MB cells used in this study are human breast cancer cells characterized by TNBC, which are generally difficult to treat with targeted agents, such as hormones or receptor-targeted drugs. Therefore, the results of this study show that GE can treat TNBC cells by increasing patient immunity.

GE is a natural ingredient that people often use as a spice that is easily available and safe. This study has shown that GE is not cytotoxic to lymphocyte cells and does not affect activated T-lymphocyte cells. In contrast, GE exerts a weak cytotoxic effect on MDA-MB cancer cells. These phenomena 
are interesting and should be explored further in terms of the underlying molecular mechanism. Whether this mechanism is also the same as that reported by Ahlina et al. (2020), which is an increase in intracellular ROS levels and inhibition of cell migration, will be interesting to prove by experiment. Usually, high ROS levels found in CSC and metastatic cancer cells are the target of anticancer agents (Meiyanto et al., 2019). The MDA-MB 231 cells also exhibit such phenomenon that can be modulated by some natural agents leading to apoptosis (Kim et al., 2018; Marvibaigi et al., 2016). The findings from molecular docking also provide hope for galangal as an agent that can help chemotherapeutic agents that have problems with PD-L1 expression in cancer cells, such as paclitaxel (Azadi et al., 2019). In this case, galangal compounds are expected to prevent the interaction of PD-L1 with PD-1 allowing T-cells to recognize cancer cells to be destroyed. This hypothesis needs to be further explored. Moreover, GE has low toxicity against lymphocyte cells which is an advantage that can be used to treat metastatic cancers. Unfortunately, our study only describes the robust affinity of GE compounds to bind PD-1 and PD-L1 in silico without comparing with a native ligand due to the lack of the well-known crystalized ligand-proteins interaction. However, this finding could give insight into the potential activity of GE to perturbate the interaction between PD-1 and PD-L1 that can be explored further under biochemical experiment.Overall, this study illustrates that GE is a safe immunopotentiation and anticancer agent that can be especially used as a cochemotherapeutic agent, to increase the sensitivity of T-cytotoxic cells and chemotherapeutic agents to cancer cells. Therefore, further research is needed to obtain more detailed information on the molecular mechanisms in vitro and in vivo. GE is an easily obtainable and safe substance. However, to be used as an anticancer agent, further research is required in terms of the appropriate dosage forms for therapeutic purposes.

\section{CONCLUSION}

GE has a synergistic cytotoxic effect when combined with cytotoxic T-cells against MDA-MB-231. The binding affinity of several of its chemical contents to PD-1 and PD-L1 may represent the underlying mechanism.

\section{ACKNOWLEDGMENTS}

This work was partly supported by Galangal Project for Immunomodulator under "Advance University Technology Application Research (PTUPT)" funding 2020 from the Ministry of Research and Technology, Republic of Indonesia.

\section{CONFLICT OF INTEREST}

The authors declare that they have no conflicts of interest regarding the publication of this paper.

\section{AUTHOR CONTRIBUTIONS}

All authors made substantial contributions to conception and design, acquisition of data, or analysis and interpretation of data; took part in drafting the article or revising it critically for important intellectual content; agreed to submit to the current journal; gave final approval of the version to be published; and agree to be accountable for all aspects of the work. All the authors are eligible to be an author as per the international committee of medical journal editors (ICMJE) requirements/guidelines.

\section{ETHICAL APPROVALS}

Ethical approval obtained from the Research Bioethics Committee of Faculty of Medicine, Universitas Islam Sultan Agung, Semarang, Indonesia (approval number, No. 010/I/2020/ Komisi Bioetik).

\section{PUBLISHER'S NOTE}

This journal remains neutral with regard to jurisdictional claims in published institutional affiliation.

\section{REFERENCES}

Ahlina FN, Nugraheni N, Salsabila IA, Haryanti S, Da'i M, Meiyanto E. Revealing the reversal effect of galangal (Alpinia galanga L.) extract against oxidative stress in metastatic breast cancer cells and normal fibroblast cells intended as a co-chemotherapeutic and anti-ageing agent. Asian Pac J Cancer Prev, 2020; 21(1):107-17.

Arul S, Rajagopalan H, Ravi J, Dayalan H. Beta-caryophyllene suppresses ovarian cancer proliferation by inducing cell cycle arrest and apoptosis. Anticancer Agents Med Chem, 2020; 20(13):1530-37.

Astani A, Reichling, J, Schnitzler P. Screening for antiviral activities of isolated compounds from essential oils. Evid Based Complement Alternat Med, 2011; 2011(253643):1-8.

Ayob AZ, Ramasamy TS. Cancer stem cells as key drivers of tumour progression. J Biomed Sci, 2018; 25(20):1-18.

Azadi S, Aboulkheyr Es H, Bazaz SR, Thiery JP, Asadnia M, Warkiani ME. Upregulation of PD-L1 expression in breast cancer cells through the formation of 3D multicellular cancer aggregates under different chemical and mechanical conditions. Biochim Biophys Acta Mol Cell Res, 2019; 1866(12):118526.

Bruttel VS, Wischhusen J. Cancer stem cell immunology: key to understanding tumorigenesis and tumor immune escape? Front Immunol, 2014; 5(360):1-13

Castagnoli L, Cancila V, Cordoba-Romero SL, Faraci S, Talarico G, Belmonte B, Lorio MV, Milani M, Volpari T, Chiodoni C, HidalgoMiranda A, Tagliabue E, Tripodo C, Sangaletti S, Nicola MD, Pupa SM. WNT signaling modulates PD-L1 expression in the stem cell compartment of triple-negative breast cancer. Oncogene, 2019; 38:4047-60.

Janeway CA Jr, Travers P, Walport M, Shlomchik MJ Immunobiology: The Immune System in Health and Disease. 5th edition. New York: Garland Science; 2001.

Chien ST, Shi MD, Lee YC, Te CC, Shih YW. Galangin, a novel dietary flavonoid, attenuates metastatic feature via PKC/ERK signaling pathway in TPA-treated liver cancer Hepg2 cells. Cancer Cell Int, 2015 ; 15(15):1-11.

Fidyt K, Fiedorowicz A, Strzadała L, Szumny A. $\beta$-caryophyllene and $\beta$-caryophyllene oxide - natural compounds of anticancer and analgesic properties. Cancer Med, 2016; 5(10):3007-17.

Hermawan A, Putri H, Utomo RY. Comprehensive bioinformatics study reveals targets and molecular mechanism of hesperetin in overcoming breast cancer chemoresistance. Mol Divers, 2019; 24:933-47.

Jaganathan SK, Supriyanto E. Antiproliferative and molecular mechanism of eugenol-induced apoptosis in cancer cells. Molecules, 2014; 17(6):6290-304.

Janssen LME, Ramsay EE, Logsdon CD, Overwijk WW. The immune system in cancer metastasis: friend Or Foe? J Immunother Cancer 2017; 5:79.

Joffre OP, Segura E, Savina, A, Amigorena S. Cross-presentation by dendritic cells. Nat Rev Immunol, 2012; 12:557-69.

Kar Mahapatra S, Bhattacharjee S, Chakraborty SP, Majumdar $\mathrm{S}$, Roy S. Alteration of immune functions and Th1/Th2 cytokine balance in nicotine-induced murine macrophages: immunomodulatory role of eugenol and $\mathrm{N}$-acetylcysteine. Int Immunopharmacol, 2011; 11(4):485-95. 
Kim MY, Choi EO, HwangBo H, Kwon DH, Ahn KI, Kim HJ, Ji SY, Hong SH, Jeong JW, Kim GY, Park C, Choi YH. Reactive oxygen species-dependent apoptosis induction by water extract of Citrus unshiu peel in MDA-MB-231 human breast carcinoma cells. Nutr Res Pract, 2018; 12(2):129-34.

Klauke AL, Racz I, Pradier B, Markert A, Zimmer AM, Gertsch J, Zimmer A. The cannabinoid CB2 receptor-selective phytocannabinoid betacaryophyllene exerts analgesic effects in mouse models of inflammatory and neuropathic pain. Eur Neuropsychopharmacol, 2014; 24(4):608-20.

Liao F, Liu L, Luo E, Hu J. Curcumin enhances anti-tumor immune response in tongue squamous cell carcinoma. Arch Oral Biol, 2018; 92:32-7.

Marvibaigi M, Amini N, Supriyanto E, Majid FAA, Jaganathan SK, Jamil S, Almaki JH, Nasiri R. Antioxidant activity and ROS-dependent apoptotic effect of Scurrula ferruginea (Jack) danser methanol extract in human breast cancer cell MDA-MB-231. PloS One, 2016; 11(7):e0150545.

Meiyanto E, Putri H, Larasati YA, Utomo RY, Jenie RI, Ikawati M, Lestari B, Yoneda-Kato N, Nakamae I, Kawaichi M, Kato JY. Anti-proliferative and anti-metastatic potential of curcumin analogue, pentagamavunon-1 (PGV-1), toward highly metastatic breast cancer cells in correlation with ROS generation. Adv Pharm Bull, 2019; 9(3):445-52.

Min HJ, Nam JW, Yu ES, Hong JH, Seo EK, Hwang ES. Effect of naturally occurring hydroxychavicol acetate on the cytokine production in T helper cells. Int Immunopharmacol, 2009; 9(4):448-54.

Pal Jain A, Singh Pawara R, Lodhia S, Singhaia A. Immunomodulatory and anti-oxidant potential of Alpinia galanga Linn. rhizomes. Pharmacogn Commun, 2012; 2:30-7.

Park CY, Tseng D, Weissman IL. Cancer stem cell-directed therapies: recent data from the laboratory and clinic. Mol Ther, 2009; 17(2):219-30.

Raniszewska A, Polubiec-Kownacka M, Rutkowska E, Domagala-Kulawik J. PD-L1 expression on lung cancer stem cells in metastatic lymph nodes aspirates. Stem Cell Rev Rep, 2019; 15:324-30.

Rom-Jurek EM, Kirchhammer N, Ugocsai P, Ortmann O, Wege AK, Brockhoff G. Regulation of programmed death ligand 1 (PD-L1) expression in breast cancer cell lines in vitro and in immunodeficient and humanized tumor mice. Int J Mol Sci, 2018; 19(2):563.

Samarghandian S, Hadjzadeh MAR, Afshari JT, Hosseini M. Antiproliferative activity and induction of apoptotic by ethanolic extract of Alpinia galanga rhizhome in human breast carcinoma cell line. BMC Complement Altern Med, 2014; 14:192.

Sceneay J, Smyth MJ, Möller A. The pre-metastatic niche: finding common ground. Cancer Metastasis Rev, 2013; 32:449-64.

Seo, JW, Cho SC, Park SJ, Lee EJ, Lee JH, Han SS, Pyo BS, Park DH, Kim BH. 1'-acetoxychavicol acetate isolated from Alpinia galanga ameliorates ovalbumin-induced asthma in mice. PloS One, 2013; 8(2):e56447.
Snyder A, Makarov V, Merghoub T, Yuan J, Zaretsky JM, Desrichard A, Walsh LA, Postow MA, Wong P, Ho TS, Hollmann TJ, Bruggeman C, Kannan K, Li Y, Elipenahli C, Liu C, Harbison CT, Wang L, Ribas A, Wolchok JD, Chan TA. Genetic basis for clinical response to CTLA-4 blockade in melanoma. N Engl J Med, 2014; 371:2189-99.

Topalian SL, Hodi FS, Brahmer JR, Gettinger SN, Smith DC, McDermott DF, Powderly JD, Carvajal RD, Sosman JA, Atkins MB, Leming PD, Spigel DR, Antonia SJ, Horn L, Drake CG, Pardoll DM, Chen L, Sharfman WH, Anders RA, Taube JM, McMiller TL, Xu H, Korman AJ, Jure-Kunkel M, Agrawal S, McDonald D, Kollia GD, Gupta A, Wigginton JM, Sznol M. Safety, activity, and immune correlates of anti-PD-1 antibody in cancer. N Engl J Med, 2012; 366:2443-54.

Upadhye AS, Rajopadhye A, Dias, L. Development and validation of HPTLC fingerprints of three species of Alpinia with biomarker galangin. BMC Complement Altern Med, 2018; 18(1):16.

Wherry EJ. T cell exhaustion. Nat Immunol, 2011; 12:492-9.

Wu J, Lanier LL. Natural killer cells and cancer. Adv Cancer Res, 2003; 90:127-56.

Yang L, Wen KS, Ruan X, Zhao YX, Wei F, Wang Q. Response of plant secondary metabolites to environmental factors. Molecules, 2018; 23(4):762.

Yu ES, Min HJ, Lee K, Lee MS, Nam JW, Seo EK, Hong JH, Hwang ES. Anti-inflammatory activity of p-coumaryl alcohol-gammao-methyl ether is mediated through modulation of interferon-gamma production in Th cells. Br J Pharmacol, 2009; 156(7):1107-14.

Zak KM, Kitel R, Przetocka, S, Golik P, Guzik K, Musielak B, Domling A, Dubin G, Holak TA. Structure of the complex of human programmed death 1, PD-1, and its ligand PD-L1. Structure, 2015; 23(12):2341-8

Zheng Y, Fang YC, Li J. PD-L1 Expression levels on tumor cells affect their immunosuppressive activity. Oncol Lett, 2019; 18(5):5399-407.

How to cite this article:

Alif I, Utomo RY, Ahlina FN, Nugraheni N, Hermansyah D, Putra A, Meiyanto E. Immunopotentiation of galangal (Alpinia galanga L.) when combined with T-cells against metastatic triple-negative breast cancer, MDA-MB 231. J Appl Pharm Sci, 2021; 11(11):053-061. 